\title{
N-Acetylcysteine Advancement of Surfactant Therapy in Experimental Meconium Aspiration Syndrome: Possible Mechanisms
}

\author{
J. KOPINCOVÁ ${ }^{1}$, D. MOKRÁ ${ }^{1}$, P. MIKOLKA ${ }^{1}$, M. KOLOMAZNÍK ${ }^{1}$, A. ČALKOVSKÁ ${ }^{1}$ \\ ${ }^{1}$ Department of Physiology, Comenius University in Bratislava, Jessenius Faculty of Medicine \\ in Martin, Martin, Slovak Republic
}

Received March 15, 2014

Accepted July 15, 2014

\begin{abstract}
Summary
Meconium aspiration syndrome (MAS) is meconium-induced respiratory failure of newborns associated with activation of inflammatory and oxidative pathways. For severe MAS, exogenous surfactant treatment is used which improves respiratory functions but does not treat the inflammation. Oxidative process can lead to later surfactant inactivation; hence, surfactant combination with antioxidative agent may enhance the therapeutic effect. Young New Zealand rabbits were instilled by meconium suspension and treated by surfactant alone, $\mathrm{N}$ acetylcysteine (NAC) alone or by their combination and oxygenventilated for $5 \mathrm{~h}$. Blood samples were taken before and $30 \mathrm{~min}$ after meconium application and $30 \mathrm{~min}, 1,3$ and $5 \mathrm{~h}$ after the treatment for evaluating of oxidative damage, total leukocyte count, leukocyte differential count and respiratory parameters. Leukocyte differential was assessed also in bronchoalveolar lavage fluid. NAC alone had only mild therapeutic effect on MAS. However, the combination of NAC and surfactant facilitated rapid onset of therapeutic effect in respiratory parameters (oxygenation index, $\mathrm{PaO}_{2} / \mathrm{FiO}_{2}$ ) compared to surfactant alone and was the only treatment which prevented neutrophil migration into the lungs, oxidative damage and lung edema. Moreover, NAC suppressed IL- 8 and IL- $\beta$ formation and thus seems to be favorable agent for improving surfactant therapy in MAS.
\end{abstract}

\section{Key words}

Meconium aspiration • Surfactant inactivation - $\mathrm{N}$-acetylcysteine

- Oxidative damage $\bullet$ Neutrophils

\section{Corresponding author}

J. Kopincová, Department of Physiology, Comenius University in Bratislava, Jessenius Faculty of Medicine in Martin, Malá Hora 4, 03601 Martin, Slovak Republic.

E-mail: jana.kopincova@jfmed.uniba.sk

\section{Introduction}

Meconium is the first newborn's stool containing huge number of substances including triglycerides, cholesterol and fatty free acids, bile acids, bilirubin, dietary fiber, hemoglobin, proteins and proinflammatory cytokines interleukin (IL) $1 \beta$, IL-6, IL-8 or tumor necrosis factor (TNF) $\alpha$ (Yamada et al. 2000, de Beaufort et al. 2003), all having great potential to inactivate pulmonary surfactant and start up inflammation if aspirated.

Aspiration of meconium occurs in the term and post-term newborns intrauterinely or perinatally mostly under conditions of hypoxia and leads to serious disease called meconium aspiration syndrome (MAS) combining mechanical obstruction of airways, pulmonary vasoconstriction, lung edema, surfactant dysfunction and oxidative and inflammatory changes associated with chemical pneumonitis. If airway suctioning, oxygen delivery and ventilatory support are not sufficient for overcoming of severe respiratory insufficiency of newborn, exogenous surfactant may be administered being the last step before extracorporeal membrane oxygenation (Findlay et al. 1996).

Exogenous surfactant replaces the function of inactivated endogenous surfactant which lies in lowering of surface tension of small airways and alveoli (Sun et al. 1993). Such surfactant-mediated increase in lung compliance reduces the demand of newborn's respiratory muscle work and improves the gas exchange, thereby lowering oxygen requirements. Moreover, if administered diluted in a way of bronchoalveolar (or lung) lavage, surfactant removes at least partially meconium from lower airways and thus prevents both the mechanical 
obstruction and proinflammatory stimuli. Enhancement of surfactant therapy can be reached by administration of undiluted surfactant bolus following previous lung lavage (Kaneko et al. 2001).

Even within the highest possible effectiveness of surfactant therapy, the meconium-induced inflammatory response persists in the lungs with miscellaneous intensity. Meconium had been shown to activate toll-like receptor 4 (TLR4) complex CD14/TLR4/MD-2 (Salvesen et al. 2010) which had been for long time thought to be associated only with bacterial lipopolysaccharides (LPS; Latz and Golenbock 2003) and which is present on different types of cells including macrophages, endothelial and epithelial cells (Andonegui et al. 2003, Skerrett et al. 2004, Xiang et al. 2010, Poledne 2013). Subsequent nuclear factor kappa B (NF-kB) activation triggers additive cytokine production which potentiates the effect of cytokines inherent in the meconium itself (Yamada et al. 2000). Chemoattracted leukocytes infiltrate the lung tissue and react by degranulation and release of proteolytic enzymes on the one hand and by production of free radicals on the other one.

Both these actions may damage tight junctions and cells themselves and what is more, inactivate exogenous surfactant lipids and proteins (Bouhafs and Jarstrand 2002, Grommes and Soehnlein 2011). Such inactivation occurs in hours or days according to seriousness of inflammation and in clinical practice has been named "postsurfactant slump" (Donn and Dalton 2009). Infants, who initially responded positively to exogenous surfactant, subsequently deteriorated and developed increasing oxygen requirements and the need of repeated surfactant doses (Katz and Klein 2006).

According to European Consensus Guidelines 2013, non-invasive methods of respiratory support such as continuous positive airway pressure (CPAP) are largely recommended in newborns with respiratory distress prior to mechanical ventilation whenever it is possible. If needed, intubation for mechanical ventilation should be accompanied by surfactant administration every time and replaced by non-invasive support as soon as possible (Sweet et al. 2013). Despite intensive investigation of new techniques of surfactant administration, use of endotracheal tube remains still the gold standard (Lopez et al. 2013). In this context, repeated need of exogenous surfactant during postsurfactant slump means also repeated intubation of the newborn and all of the accompanying risks (Sweet et al. 2013). For this reason, it may bring benefit to reduce oxidative/inflammatory processes and keep surfactant preparations active as long as possible by preventing them from inactivation.

In our previous study, we have found that combination of exogenous surfactant and budesonide managed to prevent inflammation-mediated surfactant inactivation in experimental model of MAS (Mikolka et al. 2013). Inhaled budesonide has been associated with lower adverse effects compared to systematic glucocorticoid treatment (Halliday et al. 2001), however, early postnatal glucocorticoid application generally is thought to have long-term consequences (Yeh et al. 2004, Fok 2009).

$\mathrm{N}$-acetylcysteine (NAC) is a thiol, a mucolytic agent and a precursor of L-cysteine and reduced glutathione (GSH), serving with high efficiency as a substrate for synthesis of intracellular GSH prior to direct scavenging of ROS. On molecular level, NAC was found to inhibit p38 MAP kinase, activating protein AP-1 and $\mathrm{NF}-\kappa \mathrm{B}$, to reduce expression of adhesion molecules, IL-8, TNF- $\alpha$ and IL-1 $\beta$ levels and prevent neutrophil migration and/or activation into the lung tissue (Davreux et al. 1997, Zafarullah et al. 2003, Cuzzocrea et al. 2001, Patterson et al. 2003, Rushworth and Megson 2014) thereby exerting both anti-oxidative and antiinflammatory abilities. Moreover, NAC is considered to be very safe and without adverse effects if the dosage does not exceed about 3 grams/day (Dodd et al. 2008). In lower doses it had been administered even to newborns (Walls et al. 2007) and successfully used in the treatment of acute lung injury/acute respiratory distress syndrome the group where inflammation plays role and where MAS also belongs to (Soltan-Sharifi et al. 2007). The NAC capability to reduce the viscosity of meconium by breaking disulphide bonds between protein molecules provides further possible advantage in MAS management (Ivanov 2006). Although NAC was found to prevent surfactant inactivation in MAS (Mokrá et al. 2013), the clinical outcome on respiratory parameters and possible anti-inflammatory action of NAC combined with surfactant has not been proven yet.

Having previous experience with surfactant lung lavage and administration of combined therapy in experimental rabbit model of MAS (Ševecová-Mokrá et al. 2004, Mikolka et al. 2013), we supposed that exogenous surfactant together with NAC may improve lung functions with higher efficiency compared to either treatment alone. In this pilot study, we have evaluated lung function parameters, the dynamic onset of oxidative 
damage and neutrophil migration into the lung tissue and cytokine formation between meconium-instilled animals and groups treated with surfactant or NAC monotherapy and combined therapy.

\section{Methods}

\section{General design of experiments}

Design of experiments was approved by the local Ethics Committee of Jessenius Faculty of Medicine and National Veterinary Board. Meconium collected from healthy term neonates had been lyophilized and stored at $-20{ }^{\circ} \mathrm{C}$. Immediately before use, meconium was resuspended in $0.9 \% \mathrm{NaCl}$ at a concentration of $25 \mathrm{mg} / \mathrm{ml}$. Young New Zealand white rabbits (Velaz s. r. o., ČR) of $2.5 \pm 0.4 \mathrm{~kg}$ body weight (b.w.) were anesthetized with intramuscular ketamine $(20 \mathrm{mg} / \mathrm{kg}$ b.w.; Narketan, Vétoquinol, UK) and xylazine (5 mg/kg b.w.; Xylariem, Riemser, Germany), followed by infusion of ketamine $(20 \mathrm{mg} / \mathrm{kg} / \mathrm{h})$. Tracheotomy was performed and catheters were inserted into a femoral artery and right atrium for the blood sampling and blood pressure measuring, and into a femoral vein for drug and anesthetics administration. Animals were then paralyzed with pipecuronium bromide $(0.3 \mathrm{mg} / \mathrm{kg}$ b.w. $/ 30 \mathrm{~min}$; Arduan, Gedeon Richter, Hungary) to avoid spontaneous breathing and subjected to a pressure-controlled ventilator (Beat-2, Chirana, Slovakia). All animals were then ventilated with a frequency of $30 / \mathrm{min}$, fraction of inspired oxygen $\left(\mathrm{FiO}_{2}\right)$ of 0.21 , inspiration time Ti $50 \%$, peak inspiratory pressure (PIP) to keep a tidal volume $\left(\mathrm{V}_{\mathrm{T}}\right)$ between $7-9 \mathrm{ml} / \mathrm{kg}$ b.w. and no positive endexpiratory pressure (PEEP) at this stage of experiment. After $15 \mathrm{~min}$ of stabilization, lung function parameters (PIP, PEEP) were recorded, blood gases $\left(\mathrm{PaO}_{2}\right.$ and $\mathrm{PaCO}_{2}$ ) were analyzed (RapidLab 348, Siemens, Germany) and arterial blood sample was taken for biochemical analysis to obtain basal values (BV).

\section{Meconium instillation}

Consequently, the rabbits were intratracheally administered $4 \mathrm{ml} / \mathrm{kg}$ b.w. of meconium suspension $(25 \mathrm{mg} / \mathrm{ml})$ divided into two equal portions with animal positioned to the right and left. From this moment on, animals were ventilated with $\mathrm{FiO}_{2} 1.0$ and PEEP $0.3 \mathrm{kPa}$. In the meconium-instilled animals, respiratory failure developed within $30 \mathrm{~min}$, defined as $>30 \%$ decrease in dynamic lung-thorax compliance and $\mathrm{PaO}_{2}<10 \mathrm{kPa}$ at $\mathrm{FiO}_{2}$ 1.0. In $30 \mathrm{~min}$ period of meconium action, all above-mentioned parameters were recorded.

\section{Administration of treatment}

After 30 min of meconium administration, the animals were randomly divided into four groups according to the treatment: 1) meconium without treatment (Mec group, $n=6$ ); 2) meconium with surfactant treatment (Surf group, $\mathrm{n}=6$ ); 3) meconium with $\mathrm{N}$ acetylcysteine treatment (NAC group, $n=6$ ); 4) meconium with combined surfactant and $\mathrm{N}$-acetylcysteine treatment (Surf+NAC group, $n=6$ ).

In all surfactant-treated animals, the procedure of surfactant administration proceeded in two steps described in details elsewhere (Mikolka et al. 2013). Briefly, modified porcine surfactant (Curosurf, Chiesi Farmaceutici, Italy; $80 \mathrm{mg}$ phospholipids (PL)/ml was used. At first, two lung lavages had been performed using Curosurf diluted by saline at PL concentration of $5 \mathrm{mg} / \mathrm{ml}$ and volume of $10 \mathrm{ml} / \mathrm{kg}$ b.w. After the second lavage, undiluted Curosurf was given at a dose of $100 \mathrm{mg} \mathrm{PL} / \mathrm{kg}$, $1.25 \mathrm{ml} / \mathrm{kg}$ b.w. as a supplementation dose.

In NAC-treated groups, intravenous Nacetylcysteine (10 mg/kg b.w.; ACC Injekt, Salutas Pharma GmbH, Germany) was given. All animals were oxygen-ventilated for additional $5 \mathrm{~h}$ after the treatment. Blood gases and respiratory parameters were recorded at $30 \mathrm{~min}, 1,2,3,4$, and $5 \mathrm{~h}$ after the treatment. At the end of experiments, animals were sacrificed by an overdose of anesthetics.

\section{Measurement of lung functions parameters}

Tracheal airflow was measured by a heated Fleisch head connected to a pneumotachograph. Airway pressure was registered via a pneumatic catheter placed in the tracheal tube and connected to electromanometer. Mean airway pressure (MAP) was calculated as: $\mathrm{MAP}=(\mathrm{PIP}+\mathrm{PEEP}) / 2 ; \quad \mathrm{PaO}_{2} / \mathrm{FiO}_{2}$ parameter as ratio between $\mathrm{PaO}_{2}$ and $\mathrm{FiO}_{2}$ and oxygenation index (OI) was calculated as: $\left.\mathrm{OI}=\left(\mathrm{MAPxFiO}_{2}\right) / \mathrm{PaO}_{2}\right) . \mathrm{PaO}_{2}$ and $\mathrm{PaCO}_{2}$ were analyzed periodically.

\section{Biochemical analyses of oxidative stress in arterial blood samples}

Samples of arterial blood were collected before meconium instillation and $30 \mathrm{~min}$ after meconium instillation, then $30 \mathrm{~min}, 1,3$, and $5 \mathrm{~h}$ after the treatment. All blood samples were immediately centrifuged at $1000 \mathrm{~g} / 4^{\circ} \mathrm{C}$ for $15 \mathrm{~min}$. Plasma had been taken and stored at $-80{ }^{\circ} \mathrm{C}$ for further biochemical analyses. Products of 
oxidative stress were evaluated by commercially available kits: BlueGene Rabbit Nitrotyrosine ELISA (E04N0005; Shanghai BlueGene Biotech CO., LTD) for nitrotyrosine formation (product of protein nitrosylation) and OxiSelect TBARS Assay Kit (STA-330; Cell Biolabs Inc.) for malondialdehyde/thiobarbituric reactive substances (TBARS) evaluation (product of lipid peroxidation) according to the manufacturer's instructions. The values were expressed as percentual changes of BV calculated for each animal.

\section{Counting of cells in the arterial blood samples}

In collected samples of arterial blood, total leukocyte count was determined microscopically in a counting chamber after staining by Türck. Differential leukocyte count was estimated microscopically after staining by Pappenheim. The values of total leukocyte count were expressed as a percentage of BV counted for each animal to get more precise information about the individual changes. The values of differential leukocyte count were expressed as percentual portion of each cell type.

\section{Bronchoalveolar lavage fluid cells evaluation}

After sacrificing the animal, lungs and trachea were excised. Left lungs were lavaged by saline $(0.9 \%$ $\mathrm{NaCl}, 37^{\circ} \mathrm{C}$ ) $3 \times 10 \mathrm{ml} / \mathrm{kg}$, bronchoalveolar lavage fluid (BALF) was centrifuged at $1500 \mathrm{rpm}$ for $10 \mathrm{~min}$. Total number of cells in the BALF was determined microscopically in a counting chamber. Differential count of cells in the BALF sediment was evaluated microscopically after staining by Pappenheim.

\section{Wet/dry lung weight ratio evaluation}

Strips of the right lung tissue were cut, weighed and dried at $60{ }^{\circ} \mathrm{C}$ for $24 \mathrm{~h}$ to determine wet/dry (W/D) lung weight ratio, expressing the rate of lung edema formation.

Biochemical analyses of cytokines in lung tissue homogenates

For cytokine evaluation, strips of the right lung tissue were homogenized in ice-cold PBS $(0.02 \mathrm{~mol} / \mathrm{l}$, $\mathrm{pH} 7.2$ ) for final concentration $10 \%$, subjected to two freeze-thaw cycles and centrifuged for $15 \mathrm{~min}$ at $1500 \mathrm{~g}$ according to manufacturer's instructions. Supernatants were removed and analyzed by commercial BlueGene Rabbit ELISA Kits for IL-1 $\beta$, IL-8 and TNF- $\alpha$ (E04I0010, E04I0056 and E04T0008; Shanghai
BlueGene Biotech CO., LTD). Data were expressed as $\mathrm{pg} / \mathrm{ml}$ of homogenate.

\section{Statistical analysis of results}

Statistical analyses were performed by STATISTICA (StatSoft, Inc.; ČR). Two-way analysis of variance (ANOVA) with Duncan post-hoc test was used for the parameters with dynamic changes (grouping factors "group" and "time"): $\mathrm{PaCO}_{2}, \mathrm{PaO}_{2} / \mathrm{FiO}_{2} ; \mathrm{OI}$; nitrotyrosine, TBARS, leukocyte count, leukocyte differential). Non-parametric analysis (Kruskal-Wallis ANOVA test) was used for comparison of total and differential leukocyte count in BALF, cytokine level in homogenates and edema of lung tissue. A value of $\mathrm{p}<0.05$ was considered to be statistically significant. Numeric values are expressed as mean \pm standard error of mean (SEM).

\section{Results}

\section{Lung function parameters before meconium instillation}

24 rabbits of both genders were used in this experiment. There were no differences in entry parameters (body weight, gender) and lung function parameters did not differ before meconium instillation between groups.

\section{Recovery of the therapeutic bronchoalveolar lavage (BAL) fluid}

In both surfactant-treated groups (Surf and Surf+NAC), $10 \mathrm{ml} / \mathrm{kg}$ of diluted exogenous surfactant were used for therapeutic bronchoalveolar lavage. The recovery of BAL was similar between both groups $(67.4 \pm 3.4 \%$ for Surf group and $74.8 \pm 2.7 \%$ for Surf+NAC group, $\mathrm{p}=0.14$, Mann-Whitney U test).

\section{Effect of therapy on the lung function parameters}

Meconium instillation led to significant worsening in respiratory parameters $\left(\mathrm{PaCO}_{2}, \mathrm{PaO}_{2} / \mathrm{FiO}_{2}\right.$, $\mathrm{OI}$ ) and before therapeutic intervention (30 $\mathrm{min}$ after meconium), this deterioration had been similar in all groups ( $p<0.001$ vs. BV, non-significant among groups).

The administration of NAC alone (NAC group) did not bring any effect on $\mathrm{PaO}_{2} / \mathrm{FiO}_{2}$ (Fig. 1A) and $\mathrm{PaCO}_{2}$ remained at very high levels all the time; however, there was a significant improvement in OI from the third hour of therapy ( $\mathrm{p}<0.05$ vs. Mec; Fig. 1B, 2).

Surfactant treatment improved the lung functions more effectively. Surfactant raised $\mathrm{PaO}_{2} / \mathrm{FiO}_{2}$ 
significantly in the second and the third hour after administration compared to both untreated animals and NAC-treated group $(\mathrm{p}<0.01$ and $\mathrm{p}<0.05$ vs. both (Mec and NAC) group in the $2^{\text {nd }}$ and the $3^{\text {rd }} \mathrm{h}$, respectively). OI was enhanced after surfactant administration significantly from the first hour and this improvement lasted until the end of experiment ( $p<0.01$ to 0.001 vs. Mec; $p<0.05$ to 0.001 vs. NAC; Fig. $1 \mathrm{~A}, \mathrm{~B})$ with $\mathrm{PaCO}_{2}$ reaching lower values in the fifth hour ( $\mathrm{p}<0.01$ vs. Mec, Fig. 2).

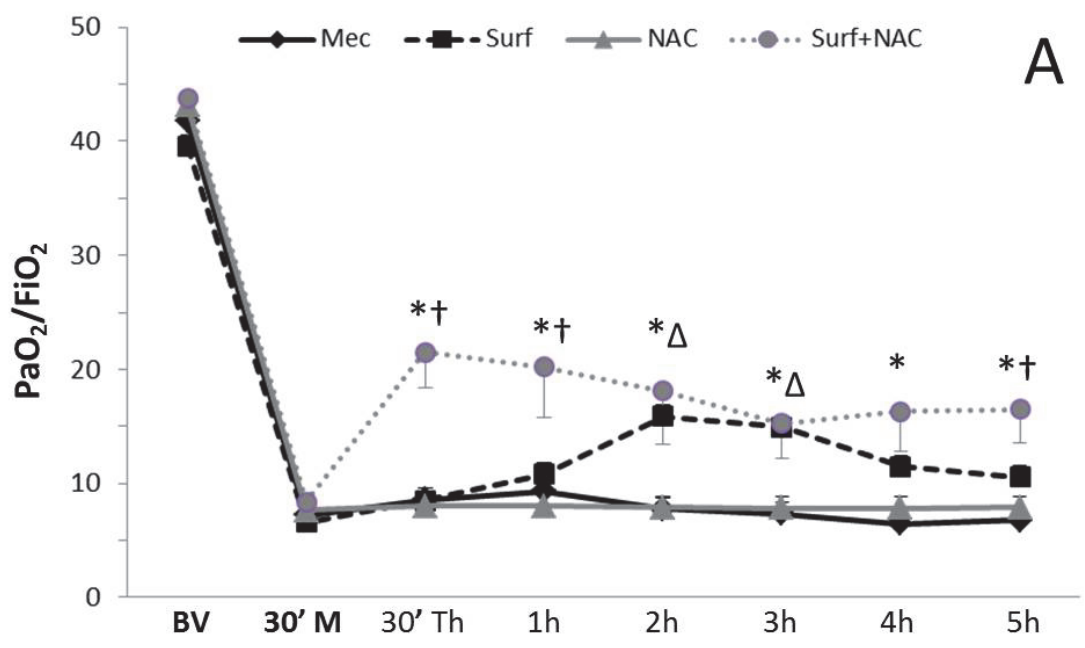

Fig. 1. $\mathrm{PaO}_{2} / \mathrm{FiO}_{2}(\mathbf{A})$ and oxygenation index (B) before meconium administration (BV), 30 min (30') after meconium (M) and therapy (Th) administration during $5 \mathrm{~h}$ of experiment. Mec - untreated group, Surf - Surfactant-only treated group, NAC - N-acetylcysteine-only treated group, Surf+NAC - Surfactant and $\mathrm{N}$-acetylcysteine treated group; $+p<0.05$ for NAC vs. Mec, $\Delta p<0.05$ to 0.001 for Surf vs. Mec and NAC, $* p<0.01$ to 0.00001 for Surf+NAC vs. $\mathrm{Mec}$ and NAC, $+\mathrm{p}<0.05$ to 0.001 for Surf+NAC vs. Surf
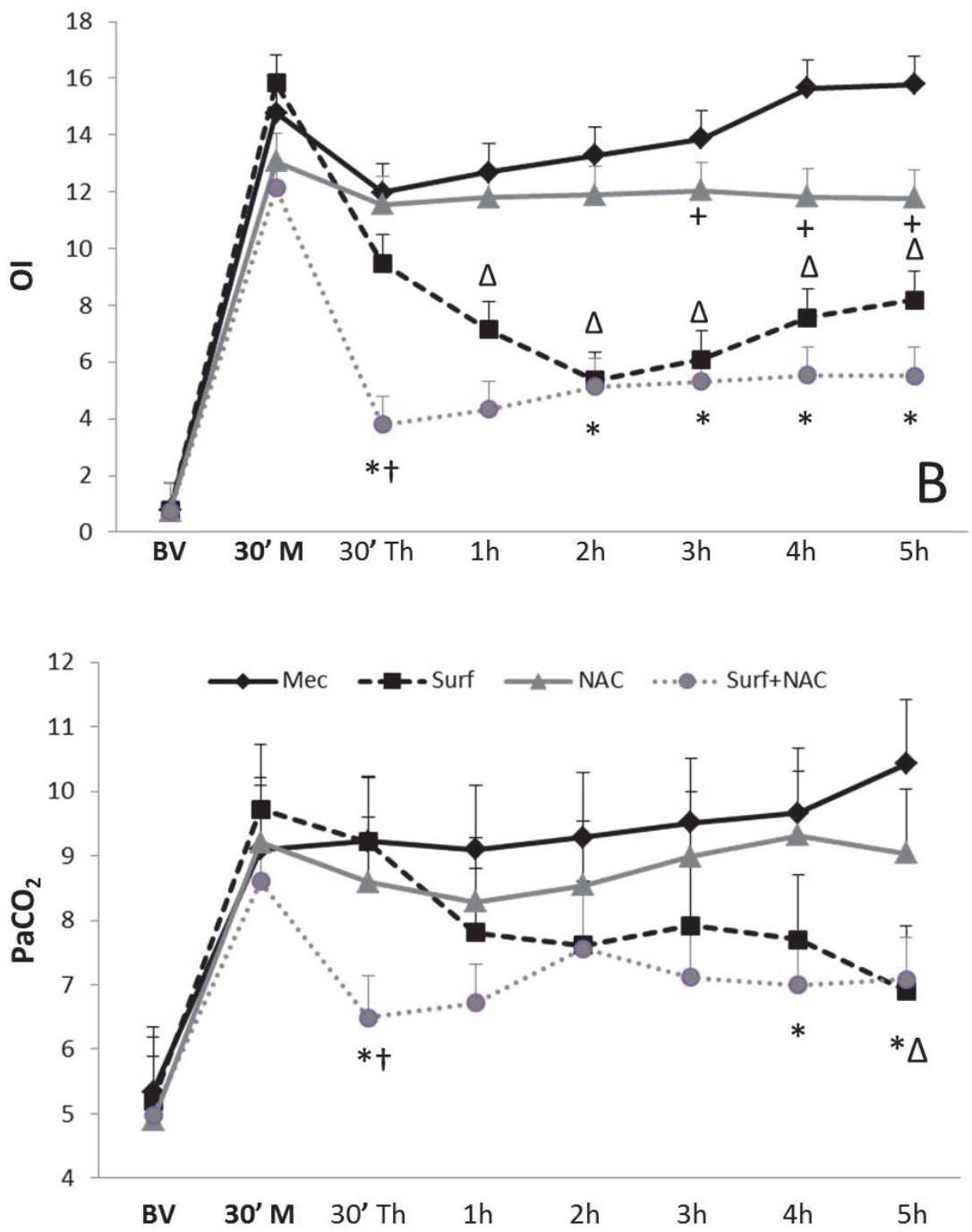

Fig. 2. $\mathrm{PaCO}_{2}$ before meconium administration (BV), 30 min (30') after meconium (M) and therapy (Th) administration during $5 \mathrm{~h}$ of experiment. Mec - untreated group, Surf - Surfactant-only treated group, NAC - N-acetylcysteine-only treated group, Surf+NAC - Surfactant and $\mathrm{N}$-acetylcysteine treated group; $\Delta p<0.05$ for Surf vs. Mec, $* p<0.05$ for Surf+NAC vs. Mec, $+p<0.05$ for Surf+NAC vs. Surf 


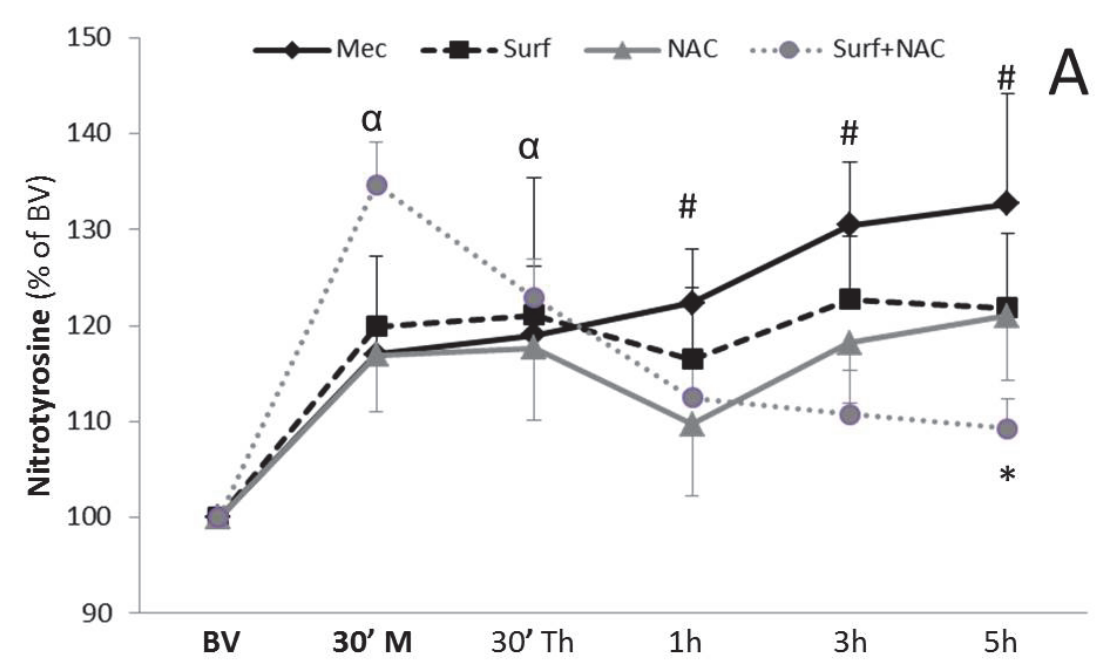

Fig. 3. Nitrotyrosine (A) and TBARS (B) formation before meconium administration (BV), 30 min (30') after meconium (M) and therapy (Th) administration during $5 \mathrm{~h}$ of experiment. Mec - untreated group, Surf - Surfactant-only treated group, NAC - N-acetylcysteine-only treated group, Surf+NAC - Surfactant and $\mathrm{N}$-acetylcysteine treated group; $\# p<0.05$ for Mec vs. BV, a $p<0.05$ to 0.01 for Surf+NAC vs. BV, $\Delta p<0.05$ to 0.001 for Surf vs. Mec, $* p<0.05$ to 0.001 for Surf+NAC vs. Mec

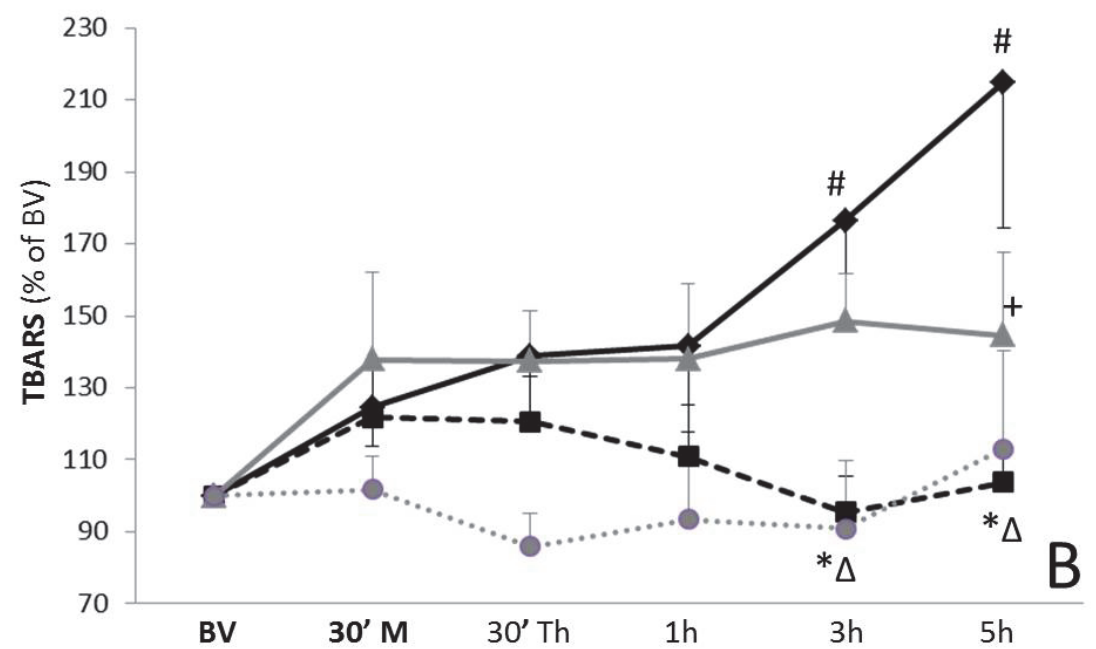

Combined therapy of surfactant and NAC revealed quick onset of the benefit. The improvement reached very high significance already in the first $30 \mathrm{~min}$ after administration of the therapy on both parameters $\mathrm{PaO}_{2} / \mathrm{FiO}_{2}$ and $\mathrm{OI} \quad(\mathrm{p}<0.01$ to 0.001 vs. $\mathrm{Mec}$ for $\mathrm{PaO}_{2} / \mathrm{FiO}_{2} ; \mathrm{p}<0.00001$ vs. Mec for OI; Fig. 1A,B) with lower $\mathrm{PaCO}_{2}$ values ( $\mathrm{p}<0.05$ vs. Surf and $\mathrm{Mec}$ in $30 \mathrm{~min}$, and vs. Mec in the $4^{\text {th }}$ and the $5^{\text {th }} \mathrm{h}$ of therapy, Fig. 2). In $\mathrm{PaO}_{2} / \mathrm{FiO}_{2}$, combined therapy had been more effective compared to NAC alone ( $p<0.01$ to 0.001 vs. NAC all the time). Moreover, the onset of the effect was more rapid compared to surfactant alone ( $\mathrm{p}<0.001$ vs. Surf in the first $30 \mathrm{~min}$ and $1 \mathrm{~h}$ of therapy) and the duration of effect remained until the end of experiment, with significant difference at $\mathrm{p}<0.05 \mathrm{vs}$. Surf at $5 \mathrm{~h}$ after the treatment (Fig. 1A). In OI and $\mathrm{PaCO}_{2}$ evaluation, the quick onset of the combined therapy compared to surfactant alone remained significant in the first $30 \mathrm{~min}(\mathrm{p}<0.001$ vs. Surf; Figs 1B, 2).
Effect of therapy on oxidative parameters

\section{Nitrotyrosine formation}

After untreated meconium administration, the increase in nitrotyrosine formation became evident in $1.5 \mathrm{~h}$ ( $\mathrm{p}<0.05$ vs. $\mathrm{BV}$, with borderline significance of $\mathrm{p}=0.08$ in the first hour after meconium). In the Surf and NAC treated groups, the level increase varied whole the time on borderline values ( $\mathrm{p}=0.051$ to $0.07 \mathrm{vs}$. $\mathrm{BV}$ ) with the onset $30 \mathrm{~min}$ after meconium administration and the only difference reached in the $3^{\text {rd }} \mathrm{h}$ in Surf group ( $<<0.05$ vs. $\mathrm{BV}$, in the $\left.5^{\text {th }} \mathrm{h} \mathrm{p}=0.051\right)$. In combined Surf $+\mathrm{NAC}$ group, the increase in nitrotyrosine formation became significant during the first $30 \mathrm{~min}$ after meconium administration ( $<00.01$ vs. BV) and this elevation lasted even 30 min after treatment administration $(\mathrm{p}<0.05$ vs. $\mathrm{BV}$ ), but then the treatment managed to decrease nitrotyrosine levels (Fig. 3A).

The inter-group statistical comparison revealed 
significant improvement in nitrotyrosine production only in Surf+NAC group in the time of $5 \mathrm{~h}$ after the treatment $(\mathrm{p}<0.05$ vs. $\mathrm{Mec})$, with borderline tendency to improvement seen at $3 \mathrm{~h}(\mathrm{p}=0.08$ vs. $\mathrm{Mec})$.

\section{TBARS formation}

The increase in TBARS concentration appeared in untreated group $3.5 \mathrm{~h}$ after meconium administration $\left(\mathrm{p}<0.05\right.$ and $\mathrm{p}<0.0001$ vs. $\mathrm{BV}$ in the $3^{\text {rd }}$ and the $5^{\text {th }} \mathrm{h}$ ). None of the treated groups showed significant increase in TBARS production during experiment (Fig. 3B).

The administration of both surfactant alone and surfactant combined with NAC ameliorated oxidative status in the $3^{\text {rd }}$ and the $5^{\text {th }} \mathrm{h}$ after the treatment $(\mathrm{p}<0.05$ and $\mathrm{p}<0.001$ vs. Mec), NAC alone had effect only at the time of $5 \mathrm{~h}(\mathrm{p}<0.05 \mathrm{vs}$. Mec $)$.

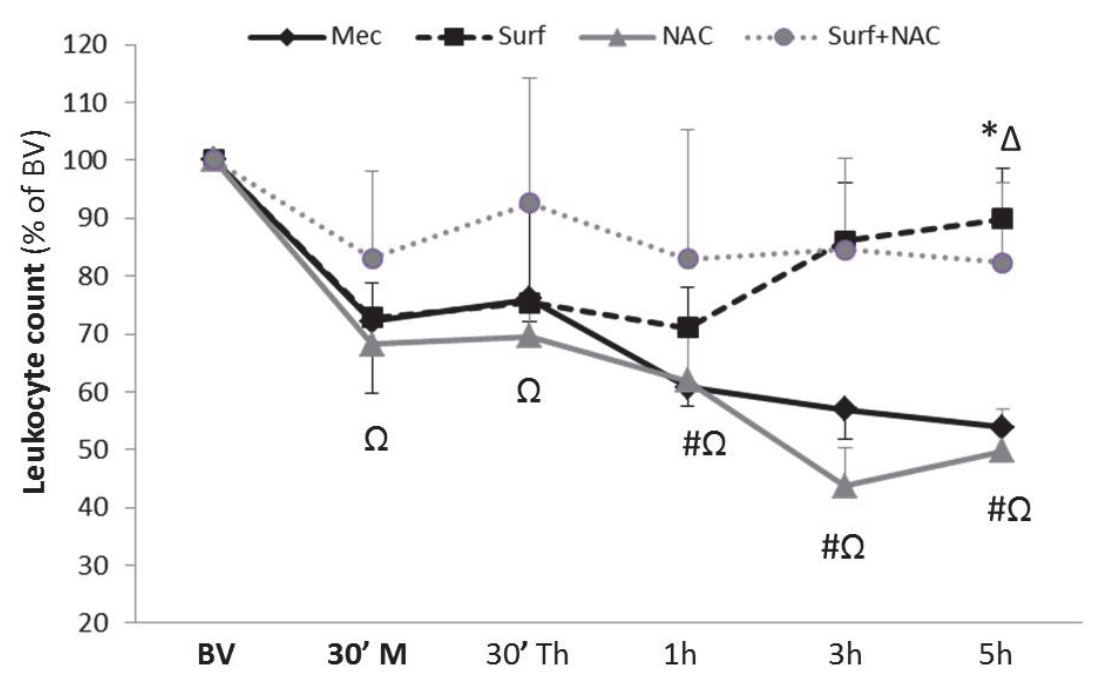

Fig. 4. Total leukocyte count in peripheral blood before meconium administration (BV), 30 min (30') after meconium (M) and therapy (Th) administration during $5 \mathrm{~h}$ of experiment. Mec - untreated group, Surf - Surfactant-only treated group, NAC - N-acetylcysteine-only treated group, Surf+NAC - Surfactant and $\mathrm{N}$-acetylcysteine treated group; $\# p<0.01$ for Mec vs. BV, $\Omega p<0.05$ to 0.001 for NAC vs. BV, $\Delta p<0.05$ for Surf vs. Mec, $* \mathrm{p}<0.05$ Surf+NAC vs. Mec

Effect of therapy on leukocyte count and migration

\section{Total leukocyte count in peripheral blood}

Administration of meconium led to significant decrease in the total count of leukocytes in peripheral blood. In untreated group, the fall reached significance $1.5 \mathrm{~h}$ after meconium ( $\mathrm{p}<0.01$ vs. BV), whereas in the NAC-treated group the fall was more pronounced and significant $30 \mathrm{~min}$ after meconium administration with no effect of therapy $(p<0.05$ to 0.001 vs. BV). In both surfactant groups (Surf and Surf+NAC), the fall of leukocytes was borderline before the therapy ( $p=0.07$ and $\mathrm{p}=0.0930 \mathrm{~min}$ after meconium administration) and the therapy managed to prevent additional fall (Fig. 4). Comparison of groups showed significant enhancement in leukocyte count in both surfactant-treated groups in the $5^{\text {th }} \mathrm{h}$ of the therapy with the tendency seen already in the $3^{\text {rd }} \mathrm{h}\left(\mathrm{p}<0.05\right.$ vs. Mec in the $5^{\text {th }} \mathrm{h}$ for Surf and Surf $+\mathrm{NAC}$; in the $3^{\text {rd }} \mathrm{h} \mathrm{p}=0.06$ vs. Mec for Surf and $\mathrm{p}=0.07$ vs. Mec for Surf+NAC).

\section{Leukocyte differential count in peripheral blood}

Meconium shifted percentual proportions in leukocyte types (Table 1). In Mec group, neutrophil demargination and consequently relative lymphocyte fall appeared in the $5^{\text {th }} \mathrm{h}$ of the experiment $(\mathrm{p}<0.001$ vs. BV for both types); this neutrophil increase (and lymphocyte decrease) reached also significant difference in comparison to NAC and Surf+NAC groups $(p<0.05$ vs. both groups).

Similar but more pronounced proportional shift was found in Surf group, with significant neutrophil abundance and lymphocyte fall in the $3^{\text {rd }}$ and the $5^{\text {th }} \mathrm{h}$ compared to basal value ( $p<0.01$ vs. BV for both types and both times) and to other groups ( $<<0.05$ in $3 \mathrm{~h}$ vs. NAC group and $\mathrm{p}<0.001$ in $5 \mathrm{~h}$ vs. NAC and Surf + NAC groups).

Neutrophil and lymphocyte changes in NAC and Surf+NAC groups were of the same kind with significance reached at $5 \mathrm{~h}$ (both $\mathrm{p}<0.05$ vs. BV).

There were no significant changes in monocyte, eosinophil and basophil percentage during experiment within or between experimental groups (Table 1; for basophils data not shown, as their occurrence is very rare and for all groups and all times the number was 0.0 to 0.1 ). 
Table 1. Differential leukocyte count in peripheral blood before meconium administration (BV), 30 min (30') after meconium (Mec) and therapy (Th) administration during $5 \mathrm{~h}$ of experiment.

\begin{tabular}{|c|c|c|c|c|c|c|}
\hline & BV & 30' Мec & 30' Th & $1 \mathrm{~h} \mathrm{Th}$ & $3 \mathbf{h}$ Th & $5 \mathrm{~h} \mathrm{Th}$ \\
\hline \multicolumn{7}{|c|}{ Neutrophils (\%) } \\
\hline $\mathrm{Mec}$ & $4.3 \pm 1.9$ & $13.5 \pm 5.9$ & $12.6 \pm 5.2$ & $10.3 \pm 2.0$ & $17.7 \pm 4.7$ & $38.3 \pm 7.7^{\text {aef }}$ \\
\hline Surf & $2.7 \pm 1.1$ & $7.4 \pm 3.1$ & $6.8 \pm 0.6$ & $8.1 \pm 1.7$ & $25.6 \pm 4.5^{\text {be }}$ & $46.1 \pm 4.9^{\text {bef }}$ \\
\hline$N A C$ & $2.8 \pm 1.3$ & $3.4 \pm 1.9$ & $4.9 \pm 2.5$ & $7.8 \pm 0.5$ & $9.1 \pm 3.1$ & $21.8 \pm 6.6^{\mathrm{c}}$ \\
\hline Surf $+N A C$ & $2.8 \pm 0.9$ & $1.9 \pm 0.2$ & $5.0 \pm 1.5$ & $9.7 \pm 4.3$ & $17.2 \pm 4.3$ & $23.1 \pm 6.8^{d}$ \\
\hline \multicolumn{7}{|c|}{ Lymphocytes (\%) } \\
\hline $\mathrm{Mec}$ & $92.3 \pm 1.8$ & $85.6 \pm 6.1$ & $84.8 \pm 4.5$ & $87.4 \pm 2.3$ & $80.7 \pm 4.8$ & $59.6 \pm 7.7^{\text {aef }}$ \\
\hline Surf & $95.6 \pm 1.4$ & $90.7 \pm 3.6$ & $92.0 \pm 0.9$ & $90.3 \pm 1.3$ & $72.2 \pm 5.0^{\text {be }}$ & $51.2 \pm 4.9^{\text {bef }}$ \\
\hline$N A C$ & $95.2 \pm 1.6$ & $94.4 \pm 1.7$ & $93.5 \pm 2.5$ & $90.6 \pm 0.5$ & $88.7 \pm 3.1$ & $76.7 \pm 6.7^{\mathrm{c}}$ \\
\hline Surf $+N A C$ & $94.8 \pm 0.5$ & $96.1 \pm 0.2$ & $93.9 \pm 1.5$ & $87.7 \pm 4.5$ & $81.5 \pm 4.7$ & $75.7 \pm 6.6^{\mathrm{d}}$ \\
\hline \multicolumn{7}{|c|}{ Monocytes (\%) } \\
\hline $\mathrm{Mec}$ & $1.6 \pm 0.6$ & $1.5 \pm 0.6$ & $1.4 \pm 0.5$ & $1.3 \pm 0.8$ & $1.2 \pm 0.3$ & $1.3 \pm 0.4$ \\
\hline Surf & $1.1 \pm 0.4$ & $0.9 \pm 0.2$ & $0.8 \pm 0.3$ & $0.7 \pm 0.4$ & $0.8 \pm 0.2$ & $1.2 \pm 0.2$ \\
\hline$N A C$ & $1.3 \pm 0.2$ & $1.3 \pm 0.3$ & $1.2 \pm 0.4$ & $1.2 \pm 0.4$ & $1.3 \pm 0.2$ & $1.2 \pm 0.4$ \\
\hline Surf $+N A C$ & $1.2 \pm 0.4$ & $0.9 \pm 0.2$ & $0.8 \pm 0.4$ & $1.1 \pm 0.5$ & $0.9 \pm 0.5$ & $0.8 \pm 0.6$ \\
\hline \multicolumn{7}{|c|}{ Eosinophils (\%) } \\
\hline $\mathrm{Mec}$ & $1.2 \pm 0.6$ & $0.9 \pm 0.6$ & $0.9 \pm 0.3$ & $0.8 \pm 0.3$ & $0.4 \pm 0.5$ & $0.9 \pm 0.4$ \\
\hline Surf & $0.6 \pm 0.3$ & $1.1 \pm 0.7$ & $0.8 \pm 0.4$ & $0.8 \pm 0.3$ & $1.1 \pm 0.4$ & $1.5 \pm 0.6$ \\
\hline$N A C$ & $0.8 \pm 0.3$ & $0.6 \pm 0.3$ & $0.9 \pm 0.4$ & $0.5 \pm 0.3$ & $0.5 \pm 0.4$ & $0.6 \pm 0.4$ \\
\hline Surf $+N A C$ & $1.1 \pm 0.3$ & $0.8 \pm 0.3$ & $0.5 \pm 0.4$ & $0.7 \pm 0.3$ & $0.5 \pm 0.3$ & $0.5 \pm 0.2$ \\
\hline
\end{tabular}

Mec - untreated group, Surf - Surfactant-only treated group, NAC - N-acetylcysteine-only treated group, Surf+NAC - Surfactant and $\mathrm{N}$-acetylcysteine treated group; ${ }^{a} \mathrm{p}<0.001$ for Mec vs. BV, ${ }^{b} p<0.01$ for Surf vs. BV, ${ }^{c} p<0.05$ for NAC vs. BV, ${ }^{d} p<0.05$ for Surf+NAC vs. BV, ${ }^{\mathrm{e}} \mathrm{p}<0.05$ for Mec and Surf vs. NAC, ${ }^{\mathrm{f}} \mathrm{p}<0.05$ for Mec and Surf vs. Surf+NAC

\section{Bronchoalveolar lavage fluid leukocytes}

At the end of experiment, left lungs were lavaged by $3 \times 10 \mathrm{ml} / \mathrm{kg}$ of saline. Recovery of BALF was similar in all groups $(76.2 \pm 3.2 \%$ for $\mathrm{Mec}$; $74.6 \pm 6.6 \%$ for Surf; $77.4 \pm 4.3 \%$ for NAC and $82.6 \pm 2.1 \%$ for Surf + NAC group, all $\mathrm{p}>0.05$ ).

The number of leukocytes in BALF after meconium administration was relatively high $\left(102 \pm 39 \times 10^{7}\right.$ in $\mathrm{ml}$ of BALF). Therapeutic intervention decreased the number of leukocytes, however, the significant effect was seen only in combined therapy $\left(11 \pm 2 \times 10^{7}\right.$ in $\mathrm{ml}$ of BALF; $\mathrm{p}<0.01$ vs. Mec) with borderline significance for NAC treatment $\left(18 \pm 2 \times 10^{7}\right.$ in $\mathrm{ml}$ of BALF; $\mathrm{p}=0.08$ vs. Mec; Table 2).

Differential leukocyte count in BALF had been also affected. Compared to Mec group, both Surf and Surf+NAC groups showed lower portion of neutrophils and higher portion of monocytes/macrophages $(p<0.05)$ with no changes in lymphocytes and eosinophils. NAC- treatment did not influence differential leukocyte count.

\section{Effect of therapy on lung tissue inflammation}

\section{Cytokine levels}

Comparison of cytokine levels in lung tissue homogenates showed decrease in IL-1 $\beta(\mathrm{p}<0.01)$ and IL$8(\mathrm{p}<0.05)$ after NAC treatment and IL-1 $\beta(\mathrm{p}<0.05)$ after Surf+NAC treatment compared to Mec group (Table 3). IL- 8 after Surf+NAC treatment was at $p=0.09$ and TNF- $\alpha$ remain unchanged in all treated groups compared to Mec.

\section{Lung edema}

Lung edema was evaluated by calculating of wet tissue weight and dry tissue weight ratio (Table 3). From all the administered therapies, only the combination of surfactant and NAC managed to prevent lung edema formation ( $p<0.01$ vs. Mec). 
Table 2. Total and differential leukocyte count in bronchoalveolar lavage fluid.

\begin{tabular}{|c|c|c|c|c|c|}
\hline & $\begin{array}{l}\text { Total count } \\
\left(\times 10^{7} / \mathbf{m l}\right)\end{array}$ & $\begin{array}{c}\text { Neutrophils } \\
(\%)\end{array}$ & $\begin{array}{c}\text { Monocytes/ } \\
\text { Macrophages } \\
\text { (\%) }\end{array}$ & $\begin{array}{c}\text { Lymphocytes } \\
\text { (\%) }\end{array}$ & $\begin{array}{c}\text { Eosinophils } \\
(\%)\end{array}$ \\
\hline $\mathrm{Mec}$ & $102.4 \pm 39.1$ & $69.0 \pm 5.1$ & $26.4 \pm 4.5$ & $1.7 \pm 0.4$ & $2.9 \pm 1.2$ \\
\hline Surf & $44.4 \pm 10.4$ & $39.8 \pm 7.2^{b}$ & $57.1 \pm 7.3^{\mathrm{b}}$ & $1.3 \pm 0.3$ & $1.8 \pm 0.6$ \\
\hline$N A C$ & $18.1 \pm 2.4$ & $58.9 \pm 9.0$ & $37.0 \pm 8.7$ & $2.5 \pm 0.9$ & $1.6 \pm 0.6$ \\
\hline Surf $+N A C$ & $11.6 \pm 2.1^{\mathrm{a}}$ & $40.1 \pm 9.5^{b}$ & $56.4 \pm 10.3^{\mathrm{b}}$ & $1.3 \pm 0.2$ & $1.2 \pm 0.7$ \\
\hline
\end{tabular}

Mec - untreated group, Surf - Surfactant-only treated group, NAC - N-acetylcysteine-only treated group, Surf+NAC - Surfactant and $\mathrm{N}$-acetylcysteine treated group; ${ }^{a} \mathrm{p}<0.01$ for Surf+NAC vs. Mec, ${ }^{b} \mathrm{p}<0.05$ for Surf and Surf+NAC vs. Mec

Table 3. Wet to dry (W/D) lung weight ratio and levels of cytokines IL-1 $\beta$, IL-8 and TNF-a in lung tissue homogenates.

\begin{tabular}{|c|c|c|c|c|}
\hline & W/D ratio & $\begin{array}{c}\text { IL-1及 } \\
(\mathrm{pg} / \mathrm{ml})\end{array}$ & $\begin{array}{c}\text { IL-8 } \\
(\mathrm{pg} / \mathrm{ml})\end{array}$ & $\begin{array}{r}\text { TNF- } \alpha \\
(\mathrm{pg} / \mathrm{ml})\end{array}$ \\
\hline $\mathrm{Mec}$ & $6.0 \pm 0.2$ & $142.0 \pm 13.0$ & $48.3 \pm 6.5$ & $35.3 \pm 2.1$ \\
\hline Surf & $5.4 \pm 0.2$ & $121.0 \pm 16.6$ & $42.6 \pm 4.5$ & $33.0 \pm 2.4$ \\
\hline$N A C$ & $6.1 \pm 0.3$ & $74.2 \pm 4.1^{\mathrm{a}}$ & $29.0 \pm 6.4^{\mathrm{b}}$ & $37.6 \pm 2.5$ \\
\hline Surf $+N A C$ & $5.0 \pm 0.1^{\mathrm{a}}$ & $95.1 \pm 15.8$ & $33.8 \pm 5.3^{\mathrm{b}}$ & $33.8 \pm 1.8$ \\
\hline
\end{tabular}

Mec - untreated group, Surf - Surfactant-only treated group, NAC - N-acetylcysteine-only treated group, Surf+NAC - Surfactant and $\mathrm{N}$-acetylcysteine treated group; ${ }^{\mathrm{a}} \mathrm{p}<0.01$ for NAC and Surf+NAC vs. Mec, ${ }^{\mathrm{b}} \mathrm{p}<0.05$ for NAC and Surf+NAC vs. Mec

\section{Discussion}

As it was expected, meconium instillation led to significant deterioration in respiratory parameters $\left(\mathrm{PaO}_{2} / \mathrm{FiO}_{2}, \mathrm{OI}, \mathrm{PaCO}_{2}\right.$ and also in $\mathrm{O}_{2}$ saturation and $\mathrm{pH}-$ data not shown) in few minutes after administration. This was associated with progressive formation of oxidative products of ongoing protein nitrosylation and lipid peroxidation (nitrotyrosine and TBARS). Here we need to note that we have expected faster onset of oxidative damage in untreated Mec group, especially for TBARS formation which became evidential up to $3.5 \mathrm{~h}$ after instillation (compare Imai et al. 2008); however, the levels of oxidative products right in the lungs could be different in comparison to levels in systemic circulation. Meconium administration also eventuated in leukocyte abundance in lungs, with high portion of neutrophils supposedly attracted by higher cytokine levels, all resulting in lung edema formation, typical for MAS (Pratesi and Dani 2012).

As we supposed, the effect of NAC alone in the treatment of MAS was rather low. There was no difference between NAC group and non-treated group in
$\mathrm{PaO}_{2} / \mathrm{FiO}_{2}$, and higher values of $\mathrm{PaCO}_{2}$ were observed due to impossibility of further increase in ventilatory pressures, to which the animals tended to respond by hypotension (data not shown). However, OI was improved from the third hour of the therapy, probably via inhibition of inflammatory processes in the lungs and at least partial preservation of endogenous surfactant function which we have previously confirmed (Mokrá et al. 2013). Administration of NAC prevented oxidative damage to both lipids and proteins (as seen from reduced TBARS and nitrotyrosine production) and led to mild enhancement in lipid peroxidation when compared to Mec group. This effect had been estimated as NAC is considered to have powerful antioxidant potential via replenishing GSH levels (Rushworth and Megson 2014). Even though NAC prevented neutrophil demarginalization, it managed to hinder neutrophil sequestration into the lungs just partially, which manifested by mild modification of leukocyte count in BAL and unchanged neutrophil percentage. There is evidence that neutrophil sequestration into the lungs can be inhibited by NAC due to reduced expression of adhesion molecules ICAM-1 and VCAM-1 (Zafarullah et 
al. 2003, Cuzzocrea et al. 2001). Decrease in neutrophil recruitment and cytokine-induced neutrophil chemoattractant (CINC) suppression was also seen in rats when repeated doses of NAC were used (Blackwell et al. 1997, Cuzzocrea et al. 2001), but not after single dose (Fan et al. 1998). In cardiac surgery patients, pretreatment by NAC diminished IL-8 levels and elastase activity in BALF and decreased the percentage of harvested neutrophils from $16.5 \%$ to $2.3 \%$ - BALF neutrophil count correlated negatively with enhanced $\mathrm{PaO}_{2} / \mathrm{FiO}_{2}$ level at borderline significance $(\mathrm{p}=0.054$, De Backer et al. 1996). However, there is also theory that NAC does not prevent neutrophil lung sequestration but do prevent neutrophil activation (Davreux et al. 1997) and in rats instilled intratracheally with LPS (which activates the same receptor complex as meconium), neither pre-treatment with the same dose of NAC as ours $(10 \mathrm{mg} / \mathrm{kg})$ managed to lower total leukocyte count and neutrophil fraction in BALF (Jansson et al. 2005). Similarly to our results, these authors did not find any improvement in lung edema formation and TNF- $\alpha$ in BALF was decreased only in cases where low LPS dose had been given. By contrast, they did not find any NACmediated improvement in BALF levels of IL-1 $\beta$, whereas the levels of IL-1 $\beta$ in lung tissue homogenates were decreased after NAC in our experiment. Taken together, the efficacy of NAC against inflammation and lung injury strongly differs not only according to dose and time management of the treatment, but also to the seriousness of induced inflammation. In our model, the presence of meconium with the content of inflammatory substances worked as strong inflammatory inductor and given dose of NAC was not sufficient to improve therapeutic results by itself.

However, enhancement was reached if the meconium had been at least partly removed from lungs by lung lavage. The procedure of diluted surfactant lavage therapy followed by bolus dose of concentrated surfactant, which was performed in our experiment, had been discussed in details elsewhere (Mikolka et al. 2013). Briefly, integration of surfactant lavage and bolus administration facilitates taking advantages of both approaches - removal of meconium which reduces mechanical obstruction and action of meconiumcontained cytokines together with sufficient replacement of inactivated endogenous surfactant. Surfactant was successfully used in the treatment of MAS in newborns almost 20 years ago (Findlay et al. 1996, Soll and Dargaville 2007). In agreement with other authors, we saw enhancement in lung function parameters $\left(\mathrm{PaO}_{2} / \mathrm{FiO}_{2}\right.$ and $\mathrm{OI}$ ) after administration of surfactant and also prevention from oxidative damage to lungs. However, in the course of the time, we saw disappearance of significance in $\mathrm{PaO}_{2} / \mathrm{FiO}_{2}$ when compared to $\mathrm{Mec}$ group in the fourth hour and later. This could mildly predicate the start-up of the process of surfactant inactivation due to inflammatory processes which normally can be seen in clinical practice (Katz and Klein 2006) and which can be result of protein nitrosylation noticed in the $3^{\text {rd }} \mathrm{h}$ after surfactant treatment.

Surfactant did not prevent leukocyte migration into the lungs, although the portion of BALF neutrophils was lower compared to untreated animals. These results are consistent with previous findings that exogenous surfactant can reduce macrophage-mediated neutrophil chemotaxis (Finck et al. 1998). Moreover, there was no improvement of inflammatory cytokines and lung edema formation at the end of experiment after surfactant-only treatment. Exogenous surfactant is considered to have also anti-inflammatory properties (Thomassen et al. 1992, Borron et al. 2000), however, there are also works which - similarly to ours - showed no effect of surfactant on cytokine production under different types of lung injury if administered as monotherapy (Wu et al. 2010, Dani et al. 2011). We may speculate about the mechanisms of cytokine suppression mediated by surfactant (see also Thomassen et al. 1994), but generally it seems that factors such as the time of surfactant administration and also the type and composition of used surfactant (especially the presence of surfactant proteins SP-A and SP-D) play role in this inconsistence between different studies.

Lower surfactant activity against inflammation had been overcome by combination of surfactant and NAC treatment in our experiments. At first, we supposed that NAC would replenish GSH levels and thus prevent oxidative impairment of surfactant proteins and lipids in the period of time. However, we found significant and very rapid onset of improvement in $\mathrm{PaO}_{2} / \mathrm{FiO}_{2}, \mathrm{PaCO}_{2}$ and OI parameters in the first 30 min after administration of the combined therapy. The significance was reached also in comparison with surfactant-only treatment which indicates that this enhancement cannot be attributed just to bronchoalveolar lavage and meconium removal. There are several possible mechanisms of such quick onset of efficacy. At first, NAC is able to cleave disulphide bonds in the mucoprotein molecules. This action that made $\mathrm{NAC}$ to be wide-used mucolytic agent, is also responsible 
for NAC ability to decrease the tenacity of the meconium (Pusterla et al. 2004) which had been previously used in newborns with meconium ileus as a non-surgical strategy (Emil et al. 2004). Moreover, NAC is able to cross cell membranes in relatively easy way resulting in quick tissue distribution after intravenous application (Rushworth and Megson 2014). Taken together, we can speculate that reduction of meconium viscosity combined with surfactant supplementation and GSH replenishment provided rapid enhancement which we have seen already in $30 \mathrm{~min}$ after administration of the therapy. Moreover, there is a molecular effect of NAC, which was found to inhibit cyclooxygenase-2 (COX2) induction in vascular smooth muscle cells through suppression of p38 mitogenactivated protein kinase pathway which is redox-sensitive (Zafarullah et al. 2003, Bernatova 2014). COX2 expression is known to be meconium-induced (Kytölä et al. 2003) and COX2-derived product thromboxane is directly responsible for LPS-induced bronchoconstriction via several cooperating mechanisms (Uhlig et al. 1996, Ermert et al. 2003). Inhibition of this signalisation may result in lower airway resistance and thus increase in lung function parameters.

Combination of surfactant and NAC managed to prevent oxidative damage to lungs and were the only treatment which brought significant improvement in nitrotyrosine levels when compared to Mec group. Nitrotyrosine production is a consequence of inducible nitric oxide synthase (iNOS) induction which is NF- $\kappa$ Bmediated and induced in MAS (Kytölä et al. 2003, Kopincová et al. 2011, 2012). On one hand, NAC suppress $\mathrm{NF}-\kappa \mathrm{B}$ activation via changes in redox state (Haddad 2002). On the other hand, NF- $\kappa B$ can be induced also by the presence of IL-1 and TNF- $\alpha$ which are contained in meconium (Yamada et al. 2000, Haddad 2002, de Beaufort et al. 2003). In this context, meconium removal by surfactant lavage prevents cytokine-induced $\mathrm{NF}-\kappa \mathrm{B}$ actions. Altogether, this improvement is probably a result of surfactant and NAC co-action, which was not so evident when these agents were administered separately.

Similar co-action was seen regarding leukocyte count and neutrophil influx into the lungs. As NAC alone moderately decreased number of cells in BALF and surfactant alone decreased neutrophil portion, working together this combination managed to keep BALF cells count of treated animals in significantly lower values with declined percentage of neutrophils, although lung tissue levels of IL- 8 were not significantly reduced $(p=0.09)$. Prevention of different inflammatory factors led to reduced lung edema formation which helped to maintain respiratory parameters improved until the end of experiment, implicating that combination of NAC and exogenous surfactant in experimental MAS may bring at least partial therapeutic benefit when compared to monotherapy. Further studies are needed to clarify detailed mechanisms of action of this combination. However, there is a promise of new approach to MAS treatment which perhaps will reach clinical use.

\section{Conflict of Interest}

There is no conflict of interest.

\section{Acknowledgements}

The authors thank M. Petrášková, M. Hutko, D. Kulíšková and Z. Remišová for technical assistance and our colleagues from Clinics of Neonatology, Jessenius Faculty of Medicine, Comenius University and University Hospital, Martin for collection of neonatal meconium. The study was supported by Project "BioMed Martin" No. 26220220187; Project APVV-0435-11 and by Grant VEGA 1/0291/12.

\section{References}

ANDONEGUI G, BONDER CS, GREEN F, MULLALY SC, ZBYTNUIK L, RAHARJO E, KUBES P: Endotheliumderived Toll-like receptor-4 is the key molecule in LPS-induced neutrophil sequestration into lungs. $J$ Clin Invest 111: 1011-1020, 2003.

BERNATOVA I: Endothelial dysfunction in experimental models of arterial hypertension: cause or consequence? Biomed Res Int 2014: Article ID 598271, 2014.

BLACKWELL TS, BLACKWELL TR, HOLDEN EP, CHRISTMAN BW, CHRISTMAN JW: In vivo antioxidant treatment suppresses nuclear factor-kB activation and neutrophilic lung inflammation. J Immunol 157: 1630$1637,1996$. 
BORRON P, MCINTOSH JC, KORFHAGEN TR, WHITSETT JA, TAYLOR J, WRIGHT JR: Surfactant-associated protein A inhibits LPS-induced cytokine and nitric oxide production in vivo. Am J Physiol 278: L840-L847, 2000.

BOUHAFS RK, JARSTRAND C: Effects of antioxidants on surfactant peroxidation by stimulated human polymorphonuclear leukocytes. Free Radic Res 36: 727-734, 2002.

CUZZOCREA S, MAZZON E, DUGO L, SERRAINO I, CICCOLO A, CENTORRINO T, DE SARRO A, CAPUTI AP: Protective effects of n-acetylcysteine on lung injury and red blood cell modification induced by carrageenan in the rat. FASEB J 15: 1187-1200, 2001.

DANI C, CORSINI I, BURCHIELLI S, CANGIAMILA V, ROMAGNOLI R, JAYONTA B, LONGINI M, PATERNOSTRO F, BUONOCORE G: Natural surfactant combined with beclomethasone decreases lung inflammation in the preterm lamb. Respiration 82: 369-376, 2011.

DAVREUX CJ, SORIC I, NATHENS AB, WATSON RW, MCGILVRAY ID, SUNTRES ZE, SHEK PN, ROTSTEIN OD: N-acetyl cysteine attenuates acute lung injury in the rat. Shock 8: 432-438, 1997.

DE BACKER WA, AMSEL B, JORENS PG, BOSSAERT L, HIEMSTRA PS, VAN NOORT P, VAN OVERVELD FJ: $\mathrm{N}$-acetylcysteine pretreatment of cardiac surgery patients influences plasma neutrophil elastase and neutrophil influx in bronchoalveolar lavage fluid. Intensive Care Med 22: 900-908, 1996.

DE BEAUFORT AJ, BAKKER AC, VAN TOL MJ, POORTHUIS BJ, SCHRAMA AJ, BERGER HM: Meconium is a source of pro-inflammatory substances and can induce cytokine production in cultured A549 epithelial cells. Pediatr Res 54: 491-495, 2003.

DODD S, DEAN O, COPOLOV DL, MALHI GS, BERK M: N-acetylcysteine for antioxidant therapy: pharmacology and clinical utility. Expert Opin Biol Ther 8: 1955-1962, 2008.

DONN SM, DALTON J: Surfactant replacement therapy in the neonate: beyond respiratory distress syndrome. Respir Care 54: 1203-1208, 2009.

EMIL S, NGUYEN T, SILLS J, PADILLA G: Meconium obstruction in extremely low-birth-weight neonates: guidelines for diagnosis and management. J Pediatr Surg 39: 731-737, 2004.

ERMERT M, KUTTNER D, EISENHARDT N, DIERKES C, SEEGER W, ERMERT L: Cyclooxygenase-2-dependent and thromboxane-dependent vascular and bronchial responses are regulated via $\mathrm{p} 38$ mitogen activated protein kinase in control and endotoxin-primed rat lungs. Lab Invest 83: 333-347, 2003.

FAN J, MARSHALL JC, JIMENEZ M, SHEK PN, ZAGORSKI J, ROTSTEIN OD: Hemorrhagic shock primes for increased expression of cytokine-induced neutrophil chemoattractant in the lung: role in pulmonary inflammation following lipopolysaccharide. J Immunol 161: 440-447, 1998.

FINCK CM, HODELL MG, MARX WH, PASKANIK AM, MCGRAW DJ, LUTZ CJ, GATTO LA, PICONE AL, NIEMAN GF: Endotoxin-stimulated alveolar macrophage recruitment of neutrophils and modulation with exogenous surfactant. Crit Care Med 26: 1414-1418, 1998.

FINDLAY RD, TAEUSCH HW, WALTHER FJ: Surfactant replacement therapy for meconium aspiration syndrome. Pediatrics 97: 48-52, 1996.

FOK TF: Adjunctive pharmacotherapy in neonates with respiratory failure. Semin Fetal Neonatal Med 14: 49-55, 2009.

GROMMES J, SOEHNLEIN O: Contribution of neutrophils to acute lung injury. Mol Med 17: 293-307, 2011.

HADDAD JJ: Science review: Redox and oxygen-sensitive transcription factors in the regulation of oxidant-mediated lung injury: role for nuclear factor-kappaB. Crit Care 6: 481-490, 2002.

HALLIDAY HL, PATTERSON CC, HALAHAKOON CW: A multicenter, randomized open study of early corticosteroid treatment (OSECT) in preterm infants with respiratory illness: comparison of early and late treatment and of dexamethasone and inhaled budesonide. Pediatrics 107: 232-240, 2001.

IMAI Y, KUBA K, NEELY GG, YAGHUBIAN-MALHAMI R, PERKMANN T, VAN LOO G, ERMOLAEVA M, VELDHUIZEN R, LEUNG YH, WANG H, LIU H, SUN Y, PASPARAKIS M, KOPF M, MECH C, BAVARI S, PEIRIS JS, SLUTSKY AS, AKIRA S, HULTQVIST M, HOLMDAHL R, NICHOLLS J, JIANG C, BINDER CJ, PENNINGER JM: Identification of oxidative stress and Toll-like receptor 4 signaling as a key pathway of acute lung injury. Cell 133: 235-249, 2008.

IVANOV VA: Meconium aspiration syndrome treatment - new approaches using old drugs. Med Hypotheses 66: 808$810,2006$. 
JANSSON AH, ERIKSSON C, WANG X: Effects of budesonide and N-acetylcysteine on acute lung hyperinflation, inflammation and injury in rats. Vascul Pharmacol 43: 101-111, 2005.

KANEKO M, WATANABE J, UENO E: Surfactant lavage and replacement in meconium aspiration syndrome with pulmonary hemorrhage. $J$ Perinat Med 29: 351-356, 2001.

KATZ LA, KLEIN JM: Repeat surfactant therapy for postsurfactant slump. J Perinatol 26: 414-422, 2006.

KOPINCOVÁ J, PÚZSEROVÁ A, BERNÁTOVÁ I: Biochemical aspects of nitric oxide synthase feedback regulation by nitric oxide. Interdiscip Toxicol 4: 63-68, 2011.

KOPINCOVÁ J, PÚZSEROVÁ A, BERNÁTOVÁ I: L-NAME in the cardiovascular system - nitric oxide synthase activator? Pharmacol Rep 64: 511-520, 2012.

KYTÖLÄ J, KÄÄPÄ P, UOTILA P: Meconium aspiration stimulates cyclooxygenase-2 and nitric oxide synthase-2 expression in rat lungs. Pediatr Res 53: 731-736, 2003.

LATZ E, GOLENBOCK DT: Receptor "cross talk" in innate immunity. J Clin Invest 112: 1136-1137, 2003.

LOPEZ E, GASCOIN G, FLAMANT C, MERHI M, TOURNEUX P, BAUD O; FRENCH YOUNG NEONATOLOGIST CLUB: Exogenous surfactant therapy in 2013: what is next? Who, when and how should we treat newborn infants in the future? BMC Pediatr 13: 165, 2013.

MIKOLKA P, MOKRÁ D, KOPINCOVÁ J, TOMČÍKOVÁ-MIKUŠIAKOVÁ L, ČALKOVSKÁ A: Budesonide added to modified porcine surfactant Curosurf may additionally improve the lung functions in meconium aspiration syndrome. Physiol Res 62 (Suppl 1): 191-200, 2013.

MOKRA D, DRGOVA A, KOPINCOVA J, PULLMANN R, CALKOVSKA A: Anti-inflammatory treatment in dysfunction of pulmonary surfactant in meconium-induced acute lung injury. Adv Exp Med Biol 756: 189-196, 2013.

PATERSON RL, GALLEY HF, WEBSTER NR: The effect of N-acetylcysteine on nuclear factor-kappa B activation, interleukin-6, interleukin-8, and intercellular adhesion molecule-1 expression in patients with sepsis. Crit Care Med 31: 2574-2578, 2003.

POLEDNE R: A new atherogenic effect of saturated fatty acids. Physiol Res 62: 139-143, 2013.

PRATESI S, DANI C: Meconium aspiration syndrome. In: Neonatology. Springer, Milan, 2012, pp 423-428.

PUSTERLA N, MAGDESIAN KG, MALESKI K, SPIER SJ, MADIGAN JE: Retrospective evaluation of the use of acetylcysteine enemas in the treatment of meconium retention in foals: 44 cases (1987-2002). Equine Veterinary Education 16: 133-136, 2004.

RUSHWORTH GF, MEGSON IL: Existing and potential therapeutic uses for N-acetylcysteine: the need for conversion to intracellular glutathione for antioxidant benefits. Pharmacol Ther 141: 150-159, 2014.

SALVESEN B, STENVIK J, ROSSETTI C, SAUGSTAD OD, ESPEVIK T, MOLLNES TE: Meconium-induced release of cytokines is mediated by the TRL4/MD-2 complex in a CD14-dependent manner. Mol Immunol 47: 1226-1234, 2010.

SEVECOVA-MOKRA D, CALKOVSKA A, DRGOVA A, JAVORKA M, JAVORKA K: Treatment of experimental meconium aspiration syndrome with surfactant lung lavage and conventional vs. asymmetric high-frequency jet ventilation. Pediatr Pulmonol 38: 285-291, 2004.

SKERRETT SJ, LIGGITT HD, HAJJAR AM, ERNST RK, MILLER SI, WILSON CB: Respiratory epithelial cells regulate lung inflammation in response to inhaled endotoxin. Am J Physiol 287: L143-L152, 2004.

SOLL RF, DARGAVILLE P: Surfactant for meconium aspiration syndrome in full term infants. Cochrane Database Syst Rev 3: CD002054, 2007.

SOLTAN-SHARIFI MS, MOJTAHEDZADEH M, NAJAFI A, REZA KHAJAVI M, REZA ROUINI M, MORADI M, MOHAMMADIRAD A, ABDOLLAHI M: Improvement by N-acetylcysteine of acute respiratory distress syndrome through increasing intracellular glutathione, and extracellular thiol molecules and anti-oxidant power: evidence for underlying toxicological mechanisms. Hum Exp Toxicol 26: 697-703, 2007.

SUN B, CURSTEDT T, ROBERTSON B: Surfactant inhibition in experimental meconium aspiration. Acta Paediatrica 82: 182-189, 1993. 
SWEET DG, CARNIELLI V, GREISEN G, HALLMAN M, OZEK E, PLAVKA R, SAUGSTAD OD, SIMEONI U, SPEER CP, VENTO M, HALLIDAY HL; EUROPEAN ASSOCIATION OF PERINATAL MEDICINE: European consensus guidelines on the management of neonatal respiratory distress syndrome in preterm infants - 2013 update. Neonatology 103: 353-368, 2013.

THOMASSEN MJ, MEEKER DP, ANTAL JM, CONNORS MJ, WIEDEMANN HP: Synthetic surfactant (Exosurf) inhibits endotoxin-stimulated cytokine secretion by human alveolar macrophages. Am J Respir Cell Mol Biol 7: 257-260, 1992.

THOMASSEN MJ, ANTAL JM, CONNORS MJ, MEEKER DP, WIEDEMANN HP: Characterization of exosurf (surfactant)-mediated suppression of stimulated human alveolar macrophage cytokine responses. Am J Respir Cell Mol Biol 10: 399-404, 1994.

UHLIG S, NÜSING R, VON BETHMANN A, FEATHERSTONE RL, KLEIN T, BRASCH F, MÜLLER KM, ULLRICH V, WENDEL A: Cyclooxygenase-2-dependent bronchoconstriction in perfused rat lungs exposed to endotoxin. Mol Med 2: 373-383, 1996.

WALLS L, BAKER CF, SARKAR S: Acetaminophen-induced hepatic failure with encephalopathy in a newborn. J Perinatol 27: 133-135, 2007.

WU H, KOBAYASHI T, WAN Q, SHI W, QIAN H, CUI X, LI W: Effects of surfactant replacement on alveolar overdistension and plasma cytokines in ventilator-induced lung injury. Acta Anaesthesiol Scand 54: 354-361, 2010.

XIANG M, FAN J, FAN J: Association of Toll-like receptor signaling and reactive oxygen species: a potential therapeutic target for posttrauma acute lung injury. Mediators Inflamm 2010: Article ID 916425, 2010.

YAMADA T, MATSUBARA S, MINAKAMI H, KOHMURA Y, HIRATSUKA M, SATO I: Chemotactic activity for polymorphonuclear leukocytes: meconium versus meconium-stained amniotic fluid. Am J Reprod Immunol 44: 275-278, 2000.

YEH TF, LIN YJ, LIN HC, HUANG CC, HSIEH WS, LIN CH, TSAI CH: Outcomes at school age after postnatal dexamethasone therapy for lung disease of prematurity. N Engl J Med 350: 1304-1313, 2004.

ZAFARULLAH M, LI WQ, SYLVESTER J, AHMAD M: Molecular mechanisms of N-acetylcysteine actions. Cell Mol Life Sci 60: 6-20, 2003. 